Original Article

\title{
The effects of short-term use of compression stockings on health related quality of life in patients with chronic venous insufficiency
}

\author{
ÖZlem Cinar Özdemir, PT, PhD ${ }^{1)^{*}}$, Serkan Sevim ${ }^{1)}$, Elif Duygu' ${ }^{1)}$, Alper TuĞral ${ }^{1)}$, \\ YESIM BAKAR ${ }^{1)}$ \\ 1) School of Physical Therapy and Rehabilitation, Abant Izzet Baysal University: 14280 Bolu, Turkey
}

\begin{abstract}
Purpose] This study was aimed to analyse the effects of short-term use of compression stockings (CS) on symptoms and QoL in patients with Chronic Venous Insufficiency (CVI). [Subjects and Methods] Based on the CEAP classification C2 and C3, 117 patients with CVI were enrolled in this study. The participants were divided into two groups. The control group refused to use CS, however, was advised to do exercises and take skin care whereas the CS group used CS and performed exercise. The data were collected by using Nottingham Health Profile (NHP), Venous Insufficiency Epidemiological and Economic Study (VEINES-QoL/Sym) and Beck Depression Inventory (BDI) at baseline and after four weeks of treatment and compared within and in between groups. [Results] The comparison of pre- and post-treatment differences between groups was statistically significant for all parameters. In the study group, pre- and post-treatment scores for each parameter were significantly different. However, elevated scores in the control group suggested worsening of the illness. [Conclusion] This study established that short-term use of CS in patients with CVI significantly improved disease specific and general QoL by reducing venous symptoms. Further studies with larger sample size are necessary to confirm these findings.

Key words: Venous insufficiency, Compression stocking, Quality of life
\end{abstract}

(This article was submitted Jan. 19, 2016, and was accepted Apr. 7, 2016)

\section{INTRODUCTION}

Chronic venous insufficiency (CVI) is characterised by the retrograde flow of blood in the lower extremity. CVI and its sequel of varicose veins and venous hypertension are among the most common disorders that affect daily life ${ }^{1)}$. The prevalence of CVI ranges between $10-40 \%$ and it mostly affects lower limb. The annual incidence of CVI is $2-6 \%$ and $1.9 \%$ in women and men, respectively ${ }^{2)}$.

The main risk factors for CVI include family history, prolonged standing, history of deep venous thrombosis, age, obesity, and pregnancy ${ }^{2}$. The venous hypertension of CVI usually begins with oedema and varicose veins and progresses to stasis cellulitis and pigmentation of skin leading into lipodermatosclerosis and ulceration ${ }^{3}$.

Since established venous insufficiency cannot be cured by pharmacological interventions alone, it is most commonly treated by non-invasive methods ${ }^{4,5}$. The compression therapy relieves CVI symptoms by improving venous function and hence is preferred among other physical therapies to treat venous and lymphatic insufficiency of lower limbs. The compression stockings (CS) and calf muscle pump exercises increase venous return and are mainstay of conservative treatment ${ }^{4,6-8)}$.

CT exerts the highest compression at the ankle which gradually decreases towards knee, thereby ensuring the upward flow of blood in the direction of heart and preventing reflux towards foot or in lateral superficial veins. The compression pressure gradient of CS, by reducing diameter of major veins, increases velocity and volume of blood flow and decreases the venous hypertension and symptoms ${ }^{9,10)}$.

*Corresponding author. Özlem Çinar Özdemir (E-mail: ozlemcinar314@hotmail.com)

(C2016 The Society of Physical Therapy Science. Published by IPEC Inc.

This is an open-access article distributed under the terms of the Creative Commons Attribution Non-Commercial No Derivatives (by-nc-nd) License $<$ http://creativecommons.org/licenses/by-nc-nd/4.0/>. 
CVI considerably affects patient's health-related quality of life (HRQoL). In many patients, the pain and discomfort of CVI affects physical mobility, working capacity and social life ${ }^{11)}$. The International Society for Vascular Surgery recommended to expand outcome measures for venous disease studies to include patient-reported measures of functioning and HRQoL. It noted that comprehensive evaluation of venous disease should include assessment of clinical outcomes and HRQoL ${ }^{12)}$. For chronic conditions like CVI, the assessment of HRQoL can provide important information on disease burden that may not be adequately captured with traditional physician-based measures of morbidity or mortality ${ }^{13}$ ).

Due to chronic nature of CVI, the long term usage of the CS may be rough considering the compliance of the patient. Therefore, the present study was aimed to analyse the effect of short term use of CS on symptoms of CVI and HRQoL in CVI patients.

\section{SUBJECTS AND METHODS}

The patients visiting outpatient clinic, at Department of Cardiovascular Surgery, Abant Izzet Baysal University Hospital Bolu, Turkey were enrolled in this study. The study was approved by the Clinical Research Ethics Committee of Abant Izzet Baysal University Faculty of Medicine (IB.30.2.ABÜ.0.20.05.04-050.01.04-60).

Inclusion criteria were patients without prior treatment for CVI or varicose vein surgery and for those the disease was categorised as $\mathrm{C} 2$ and $\mathrm{C} 3$ according to CEAP classification. Exclusion criteria included presence of deep vein thrombosis, congestive heart failure, malignancy, patients having more advanced skin changes such as lipodermatosclerosis skin ulcers or other dermatological disease with pruritus, and patients who had ongoing use of CS.

All patients enrolled were given detailed explanation of the study following which informed consent was obtained from them. A questionnaire including demographic information, occupational details, and relevant medical history were distributed to them. The generic, disease specific HRQoL, and depression-related questionnaire was requested from 126 patients.

The Turkish version of Nottingham Health Profile (NHP) was used to measure a generic HRQoL. It contains 38 questions with assigned individual score from six different categories such as energy level $(E L ; n=3)$, pain $(P ; n=8)$, emotional reaction $(\mathrm{ER} ; \mathrm{n}=8)$, sleep $(\mathrm{S} ; \mathrm{n}=5)$, social isolation (SI; $\mathrm{n}=5)$, and physical abilities $(\mathrm{PA} ; \mathrm{n}=8)$. The sum of maximum scores for all categories was 100 . For calculation of final score in each category, variation in number of items per category was rationalised by computing percentage score (i.e., each sum was multiplied by 100 and divided by the number of items in the category). Possible scores ranged from 0 (indicating all "no" answers in that category or absence of distress) to 100 (all "yes" answers indicating maximal distress). Therefore, the highest score indicated worse outcomes. The reliability and validity of Turkish NHP has been demonstrated earlier ${ }^{14)}$.

The questionnaire on 26 items from 2 categories of VEINES-QoL/Sym measured severity of symptoms of CVI and its impact on HRQoL from patient's perspective. The five different frequencies (always, a few times a week, once a week, once in a few weeks, and never) for symptoms fullness of lower extremities, pain, swelling, night cramps, heat/burning sensation, restless legs, itching, tingling/stinging sensation, and throbbing under 10 different items were assessed. Limitations in daily activities ( 9 items), greatest intensity during the day $(1 \mathrm{item})$, change over the past year $(1 \mathrm{item})$, and psychological impact ( 5 items) were covered by the HRQOL scale of 2 to 7 points for response on intensity, frequency, or agreement. Venous symptoms that are part of VEINES QoL/Sym were assessed. The score for each item ranged between 0-6. The highest score indicated better outcomes in VEINES-QoL and on VEINES-Sym scale. VEINES-QoL/Sym; Turkish validity and reliability were established by study of Kutlu et $\mathrm{al}^{15)}$.

The Beck Depression Inventory (BDI) consists of 21 items; it is a self-report rating inventory that measures characteristic of attitude and symptoms of depression. The score for each item ranges between $0-3$. The higher scores indicate worsened condition. Turkish validity and reliability were established by Ulusoy et $\mathrm{al}^{16)}$

The 126 patients were divided into study group and control group. The study group included 44 patients who regularly used CS and remaining 82 patients who did not use CS were included in control group.

The patients were trained for how to use and maintain CS. The class 2 CS (JOBST brand) of height below knee and pressure gradient of 23-32 mmHg were used. The patients were asked to wear CS as soon as they wake up in the morning and take it off before going to bed. They were asked to use CS for a period of four weeks, exercise regularly and apply skin care moisturiser ( $\mathrm{pH}$ 5.5). The exercises prescribed were ankle pumping and heel lifts (3 sets of 10 repeats) and daily walk of 30-45 minutes. The patients were warned that they should not wear CS while sleeping due to high resting pressure.

The patients (without use of CS) in the control group were also prescribed same exercises and skin care. All assessments were repeated after a four-week treatment.

The Statistical Program for Social Sciences (SPSS 18.0, SPSS Inc., Chicago, IL, USA) was used for statistical analysis. Quantitative data were presented as mean and standard deviation and qualitative data as percentage (\%) and frequency (n). An independent t-test was used to compare the differences in venous symptoms, depression and HRQoL scores between groups. P value of $\leq 0.05$ was considered as statistically significant.

\section{RESULTS}

Of the 203 patients with CVI interviewed for this study, 77 were excluded due to habitants of town or village ( $\mathrm{n}=33$ ), 
absence of inclusion criteria $(\mathrm{n}=27)$, and rejection to participate into study $(\mathrm{n}=17)$. The remaining 126 patients were enrolled into the study: Study group ( $n=44)$ and Control group $(n=82)$. Nine patients ( 2 from study group and 7 from control group) did not undergo last evaluation. Thus, the study was completed with 117 patients (73 females and 44 males): Study group $(n=42)$ and Control group $(n=75)$. The average age of patients was $60.9 \pm 9.4$ years in study group and $63.1 \pm 4.9$ years for patients in control group. The height $(\mathrm{cm})$, bodyweight $(\mathrm{kg})$ and body mass index (BMI) $(\mathrm{kg} / \mathrm{m})$ for patients in both groups were comparable (Table 1).

There were significant differences between groups for VEINES/Sym sub-parameters, NHP, BDI, VEINES-QoL and VEINES/Sym total scores before and after receiving treatment $(\mathrm{p}<0.001)$ (Table 2$)$. Furthermore, pre- and post-treatment total score differences for each group were evaluated and maximum differences were found in Study group for the scores of NHP, BDI, VEINES-QoL, and VEINES/Sym (Table 3).

\section{DISCUSSION}

The present study showed that short-term use of CS in CVI patients has decreased symptoms and significantly improved quality of life in these patients.

The compression treatment for venous insufficiency in lower extremity has been used for hundreds of years since Hippocrates. The compression treatment that applies external pressure is a gold standard for CVI treatment ${ }^{17)}$. The most prevalent among the compression treatments is $\mathrm{CS}^{18}$.

The reduction in venous reflux due to application of compression below knee is well known ${ }^{19)}$. In 112 CVI patients, the use of CS (pressure 30-40 mmHg) for one month significantly improved lower extremity pain, oedema, activity tolerance, depression, sleep disorders and $\mathrm{QoL}^{9}{ }^{9}$. In this study, CS of below knee length was preferred due to its comfort, improvement in CS calf muscle pump, and low cost.

CS decreases venous symptoms such as pain, oedema, stasis, and skin changes ${ }^{20)}$. The venous symptoms were improved by the use of class $2(30-40 \mathrm{mmHg})$ and class $3(40-50 \mathrm{mmHg})$ CS for six weeks ${ }^{21)}$. Similarly, a significant decrease in symptom severity (pain, depression, swelling, sleep) and increase in activity tolerances were observed in CVI patients after use of CS for one month ${ }^{9}$. The use of CS improved pain and symptoms in $90 \%$ patients with $\mathrm{CVI}^{22}$. In line with this, significant improvement in all venous symptoms was observed in CVI patients using CS. The decrease in venous symptom scores suggests importance of short-term CS usage.

The difficulty in wearing CS, financial burden, discomfort of heat and tightness of stocking are responsible for low

Table 1. Demographic and clinical features of the patients

\begin{tabular}{lcc}
\hline & $\begin{array}{c}\text { Study group } \\
\mathrm{n}=42\end{array}$ & $\begin{array}{c}\text { Control group } \\
\mathrm{n}=75\end{array}$ \\
& $\mathrm{X} \pm \mathrm{SD}$ & $\mathrm{X} \pm \mathrm{SD}$ \\
\hline Age (years) & $60.9 \pm 9.4$ & $63.1 \pm 4.9^{*}$ \\
Height $(\mathrm{m})$ & $1.63 \pm 0.5$ & $1.63 \pm 0.0$ \\
Weight $(\mathrm{kg})$ & $81.1 \pm 11.6$ & $79.8 \pm 9.5$ \\
BMI $\left(\mathrm{kg} / \mathrm{m}^{2}\right)$ & $30.2 \pm 4.3$ & $29.8 \pm 3.7$ \\
\hline
\end{tabular}

*Values are mean $\pm \mathrm{SD},{ }^{*} \mathrm{p}<0.05$
Table 2. Comparison of differences for VEINES-QoL, NHP and BDI measurements of the patients between groups $(\mathrm{n}=117)$

\begin{tabular}{lcc}
\hline & Study group & Control group \\
& $\mathrm{n}=42$ & $\mathrm{n}=75$ \\
& $\mathrm{X} \pm \mathrm{SD}$ & $\mathrm{X} \pm \mathrm{SD}$ \\
\hline VEINES/Sym & $6.0 \pm 7.0$ & $-1.6 \pm 2.3^{*}$ \\
VEINES-QoL & $8.9 \pm 11.9$ & $-3.5 \pm 3.8^{*}$ \\
NHP & $-47.6 \pm 93.0$ & $17.0 \pm 18.2^{*}$ \\
BDI & $-3.8 \pm 8.2$ & $1.3 \pm 1.6^{*}$ \\
\hline
\end{tabular}

*Values are mean $\pm \mathrm{SD},{ }^{*} \mathrm{p}<0.05$

Table 3. Comparison of pre and post treatment scores for groups $(n=75)$

\begin{tabular}{llcc}
\hline \multirow{2}{*}{ VEINES/Sym } & $\begin{array}{c}\text { Pre treatment } \\
\mathrm{X} \pm \mathrm{SD}\end{array}$ & $\begin{array}{c}\text { Post treatment } \\
\mathrm{X} \pm \mathrm{SD}\end{array}$ \\
\hline \multirow{2}{*}{ VEINES-QoL } & Study group & $22.4 \pm 7.5$ & $28.5 \pm 9.7^{*}$ \\
& Control group & $29.2 \pm 10.1$ & $27.6 \pm 9.8^{*}$ \\
\multirow{2}{*}{ NHP } & Study group & $67.8 \pm 13.3$ & $76.7 \pm 15.5^{*}$ \\
& Control group & $76.8 \pm 16.7$ & $73.3 \pm 16.0^{*}$ \\
\multirow{2}{*}{ BDI } & Study group & $213.8 \pm 157.1$ & $166.1 \pm 124.2^{*}$ \\
& Control group & $182.0 \pm 118.6$ & $198.0 \pm 120.5^{*}$ \\
\hline
\end{tabular}

*Values are mean $\pm \mathrm{SD},{ }^{*} \mathrm{p}<0.05$ 
compliance of CS use in CVI patients. Suehiro et al. indicated that $20 \%$ of CVI patients in all age groups refused compression treatment ${ }^{23}$. Raju et al. reported that $63 \%$ of the patients failed to adapt to $\mathrm{CS}^{20)}$. Similarly, $64 \% \mathrm{CVI}$ patients enrolled in this study refused to wear CS. Based on review of patients' self-report, the Mediterranean climate characteristics of hot weather, high cost of compression stockings, and difficulty to wear were the possible reasons. Moreover, in $82 \%$ patients with elementary education graduates refused to use CS.

There is no consensus on the duration of usage of $\mathrm{CS}^{19-24)}$. It is known that venous hypertension increases after removing stockings. In a study comparing the duration of CS usage, the use of CS for entire day is more beneficial than for only half day $^{24)}$. In order to decrease ambulatory venous hypertension and to obtain maximum benefits, patients were asked to wear CS all day long. The CS usage in patients was regularly checked via telephone interviews.

Although venous diseases are highly prevalent, its effect on daily activities and quality of life are not investigated thoroughly. Both general and disease-specific QoL are accepted as a standard to determine changes in QoL. The QoL measurement enables better understanding of impact of the disease while evaluating specific problem ${ }^{25}$.

In this study, disease-specific QoL was assessed along with VEINES-QoL whereas general QoL was assessed with NHP. At the end of one month, significant improvement was observed in venous symptoms, VEINES-QoL scores and NHP parameters in group that used CS than that did not use CS. Thus CS usage improved overall QoL suggested by improvement in both disease-specific and general QoL scores.

In earlier study, the use of two different CS for a two-week duration was found to be beneficial for QoL in both groups ${ }^{26)}$. The use of class 1 (10-15 mmHg) CS for four weeks significantly increased QoL compared with and placebo pressure (3-6 $\mathrm{mmHg}$ ) stockings ${ }^{27}$. In a similar study, it was observed that a four-week use of CS increases QoL and improves symptoms of $\mathrm{CVI}^{28)}$.

The decrease of QoL in CVI is based on physical function and mobility in addition to depression and social isolation. Depression limits performance in physical, social, and personal activities leading to disability ${ }^{27}$. It was reported that $68 \%$ of the patients with venous ulceration suffer fear, depression, social isolation, anger, anxiety, and negative self-image ${ }^{29)}$. However, there is inadequate research on evaluation of depression level in venous diseases and use of scales in directly evaluating depression. In earlier study in patients with venous ulcers and BDI, the scale is used to determine presence of various levels of depression ${ }^{30)}$. In this study, depression was assessed by BDI and short-term use of CS decreased venous symptoms in CVI patients, improved daily activities, independence levels and thus significantly decreased depression levels when baseline and final BDI results were compared in the study group. Therefore, regular and long-term use of CS will improve well being of CVI patients.

This study was aimed to assess short-term effects of CS use in CVI patients. Although these patients should have been followed up for longer term, long-term monitoring was not possible due to transportation difficulties, family reasons, and financial problems. Nevertheless, we contacted the patients from control group and educated them about the short-term benefits of CS use.

Due to risk of development of venous ulcers in the advanced stages of CVI, the regular use of stocking starting from the early stages is recommended to prevent occurrence of CVI symptoms. Further studies are necessary to evaluate the effect of CS use by CVI patients in Turkish economy and financial burden on CVI individuals in Turkey. Based on the findings of this study, if the patients could be convinced to use CS for short-term duration, the favourable effects will promote long-term use.

\section{REFERENCES}

1) White JV, Ryjewski C: Chronic venous insufficiency. Perspect Vasc Surg Endovasc Ther, 2005, 17: 319-327. [Medline] [CrossRef]

2) Bergan JJ, Schmid-Schönbein GW, Smith PD, et al.: Chronic venous disease. N Engl J Med, 2006, 355: 488-498. [Medline] [CrossRef]

3) Beebe-Dimmer JL, Pfeifer JR, Engle JS, et al.: The epidemiology of chronic venous insufficiency and varicose veins. Ann Epidemiol, 2005, 15: 175-184. [Medline] [CrossRef]

4) Couzan S, Leizorovicz A, Laporte S, et al.: A randomized double-blind trial of upward progressive versus degressive compressive stockings in patients with moderate to severe chronic venous insufficiency. J Vasc Surg, 2012, 56: 1344-1350.e1. [Medline] [CrossRef]

5) Pfisterer L, König G, Hecker M, et al.: Pathogenesis of varicose veins-lessons from biomechanics. Vasa, 2014, 43: 88-99. [Medline] [CrossRef]

6) Ogiwara S: Calf muscle pumping and rest positions during and/or after whirlpool therapy. J Phys Ther Sci, 2001, 13: 99-105. [CrossRef]

7) Uchida M, Katoh M: Verification effect tech used prev deep-vein thromb. J Phys Ther Sci, 2011, 23: 243-245. [CrossRef]

8) Rhee H, Yu J, Kim S: Influence of compression types on hand function: a preliminary investigation. J Phys Ther Sci, 2011, 23: 477-480. [CrossRef]

9) Motykie GD, Caprini JA, Arcelus JI, et al.: Evaluation of therapeutic compression stockings in the treatment of chronic venous insufficiency. Dermatol Surg, 1999, 25: 116-120. [Medline] [CrossRef]

10) Szewczyk MT, Cwajda-Białasik J, Jawień A: Prevention of recurrent venous ulceration. Postepy Dermatol Alergol, 2012, 4: 308-312. [CrossRef]

11) Wong IK, Andriessen A, Charles HE, et al.: Randomized controlled trial comparing treatment outcome of two compression bandaging systems and standard care without compression in patients with venous leg ulcers. J Eur Acad Dermatol Venereol, 2012, 26: 102-110. [Medline] [CrossRef]

12) McDaniel MD, Nehler MR, Santilli SM, et al.: Extended outcome assessment in the care of vascular diseases: revising the paradigm for the 21st century. Ad Hoc Committee to Study Outcomes Assessment, Society for Vascular Surgery/International Society for Cardiovascular Surgery, North American Chapter. J Vasc Surg, 2000, 32: 1239-1250. [Medline] [CrossRef]

13) Ozdemir ÖC, Bakar B, Ankarali H: The relationship between venous insufficiency epidemiological and economic study-quality of life/symptoms and Not- 
tingham health profile instruments in older adults with chronic venous insufficiency. Top Geriatr Rehabil, 2012, 28: 269-274. [CrossRef]

14) Kücükdeveci AA, McKenna SP, Kutlay S, et al.: The development and psychometric assessment of the Turkish version of the Nottingham Health Profile. Int J Rehabil Res, 2000, 23: 31-38. [Medline] [CrossRef]

15) Kutlu A, Yilmaz E, Ceçen D, et al.: The Turkish validity and reliability of the venous insufficiency epidemiological and economic study-quality of life/symptoms scales. Angiology, 2011, 62: 329-337. [Medline] [CrossRef]

16) Ulusoy M, Sahin NH, Erkmen H: Turkish version of the Beck Anxiety Inventory: psychometric properties. J Cogn Psychother, 1998, 12: 163-172.

17) Rhee H, Kim S, Yu J: Difference in movement magnitude according to the type of compression therapy used on healthy subjects. J Phys Ther Sci, 2013, 25: 77-79. [CrossRef]

18) Partsch H, Flour M, Smith PC, International Compression Club: Indications for compression therapy in venous and lymphatic disease consensus based on experimental data and scientific evidence. Under the auspices of the IUP. Int Angiol, 2008, 27: 193-219. [Medline]

19) Spence RK, Cahall E: Inelastic versus elastic leg compression in chronic venous insufficiency: a comparison of limb size and venous hemodynamics. J Vasc Surg, 1996, 24: 783-787. [Medline] [CrossRef]

20) Raju S, Hollis K, Neglen P: Use of compression stockings in chronic venous disease: patient compliance and efficacy. Ann Vasc Surg, $2007,21: 790-795$. [Medline] [CrossRef]

21) Chant AD, Magnussen P, Kershaw C: Support hose and varicose veins. Br Med J (Clin Res Ed), 1985, 290: 204. [Medline] [CrossRef]

22) Cataldo JL, de Godoy JM, de Barros N: The use of compression stockings for venous disorders in Brazil. Phlebology, 2012, 27: 33-37. [Medline] [CrossRef]

23) Suehiro K, Morikage N, Yamashita O, et al.: Adherence to and efficacy of different compression methods for treating chronic venous insufficiency in the elderly. Phlebology, 2015, 0268355515608992. [Medline]

24) Belczak CE, de Godoy JM, Ramos RN, et al.: Is the wearing of elastic stockings for half a day as effective as wearing them for the entire day? Br J Dermatol, 2010, 162: 42-45. [Medline] [CrossRef]

25) van Korlaar I, Vossen C, Rosendaal F, et al.: Quality of life in venous disease. Thromb Haemost, 2003, 90: 27-35. [Medline]

26) Jeanneret C, Karatolios K, von Planta I: Impact of compression stockings on calf-vein diameters and on quality of life parameters in subjects with painful legs. Vasa, 2014, 43: 268-277. [Medline] [CrossRef]

27) Vayssairat M, Ziani E, Houot B: [Placebo controlled efficacy of class 1 elastic stockings in chronic venous insufficiency of the lower limbs]. J Mal Vasc, 2000, 25: 256-262. [Medline]

28) Al Shammeri O, AlHamdan N, Al-Hothaly B, et al.: Chronic Venous Insufficiency: prevalence and effect of compression stockings. Int J Health Sci Qassim, 2014, 8: 231-236. [Medline]

29) Phillips T, Stanton B, Provan A, et al.: A study of the impact of leg ulcers on quality of life: financial, social, and psychologic implications. J Am Acad Dermatol, 1994, 31: 49-53. [Medline] [CrossRef]

30) Salomé GM, Blanes L, Ferreira LM: Evaluation of depressive symptoms in patients with venous ulcers. Rev Bras Cir Plast, 2012, 27: 124-129. 